\title{
Voice Production during a Weightlifting and Support Task
}

\author{
Robert F. Orlikoff \\ Department of Speech-Language Pathology, Seton Hall University, South Orange, N.J., USA
}

\section{Key Words}

Phonation - Electroglottography · Aerodynamics • Laryngeal valving $\cdot$ Effort closure

\begin{abstract}
Although effort closure techniques have a long history in the treatment of hypofunctional and psychogenic voice disorders, there have been surprisingly few studies of their specific laryngeal and phonatory effects. The present study was designed to provide preliminary data on physiologic changes in voice production associated with a weightlifting and support maneuver. Twenty vocally healthy subjects (10 men and 10 women) lifted hand-held weights and steadily supported them with outstretched arms as they either sustained comfortable phonation or repeated the syllable /pi/. Both the male and female subjects showed an increase in the electroglottographic contact quotient, long-term $F_{0}$ variability, and estimated laryngeal airway resistance attributable to an elevated driving pressure. Conversely, there were no significant changes in mean $\mathrm{F}_{0}$, pitch perturbation quotient (jitter), or phonatory airflow between the pre-lift and lift portions of their voice production, regardless of the amount of weight supported. The results of this study indicate that simultaneous phonation and weightlifting is associated with increased laryngeal airway resistance characterized by an elevation in driving pressure and medial compression of the vocal folds. Implications for an improved understanding of normal vocal physiology and for the therapeutic use of such air-trapping exercises are addressed.
\end{abstract}

Copyright $\odot 2008$ S. Karger AG, Basel

\section{KARGER}

Fax +4161306 1234

E-Mail karger@karger.ch

www.karger.com (c) 2008 S. Karger AG, Basel

$1021-7762 / 08 / 0604-0188 \$ 24.50 / 0$

Accessible online at: www.karger.com/fpl

\section{Introduction}

The primary function of the larynx is to valve the flow of air into and out of the lower respiratory system [1]. By adjusting the glottal aperture, the vocal folds not only help protect and clear the airway, but also allow the entrapment and subsequent pressurization of air that helps stabilize the chest wall [2-7]. Restraining the collapse of the rib cage, this supportive closure allows the muscles of the trunk and limbs to perform with greater effectiveness. The maintenance of alveolar (and thus intratruncal) pressure during lifting has been shown to not only assist the support of the pectoral girdle, but also to alleviate part of the load on the vertebral column $[8,9]$. Even moderate levels of physical exertion may be associated with this type of 'adductory bias' [10-12], which is why such effort closure or air-trapping activities as lifting, pushing, and pulling are commonly employed in therapeutic exercises for patients presenting with vocal hypofunction and/or glottal incompetence [13-21].

Yamaguchi et al. [22] reported that 3 patients with glottal inefficiency and inadequate glottal closure were able to increase both vocal intensity and airflow stability through the use of pushing exercises. In 1 case, the electroglottogram (EGG) from a patient with sulcus vocalis showed a more rapid increase in vocal-fold contact, a rounder peak, and a longer duration of contact following therapeutic pushing. Ramig and Scherer [23], Dromey et al. [24], Ramig and Dromey [25] and Ramig et al. [26] have also integrated such activities as 'pushing the hands together or pushing down or lifting up on the arms of a 
chair or table while phonating' in their approach to voice treatment for hypokinetic dysarthria. Noting similar EGG changes, they have reported clinically significant improvement in vocal intensity and speech prosody for several of their patients. Still others [27-29] have claimed that the increased medial compression attained through this primitive closure mechanism can be used effectively to lower the speaking fundamental frequency $\left(\mathrm{F}_{0}\right)$ or to suppress inappropriate vocal behavior of functional origin.

Despite widespread clinical implementation, there have been few studies of the vocal effects of simultaneous upper-limb effort or other forms of physical exertion. Otis and Clark [30] and Doust and Patrick [10] have reported that vocalizations produced by normal subjects while running on a treadmill were typically louder, higher in pitch, and occasionally perceived to be more tremulous and breathy. Even for patients with glottal inefficiency, several authors $[14,17,29]$ have warned of the potentially abusive consequences of inducing vocal hyperfunction through strenuous effort closure activities. Indeed, loud speech accompanied by rapid and effortful body movement may be largely responsible for the higher incidence of vocal fatigue and vocal-fold pathology among cheerleaders and aerobics instructors [31-35].

To determine if, when, and how an exercise is to be incorporated in voice treatment, it is necessary to document its specific physiologic effects. A better understanding of the normal response to pushing, pulling and lifting will allow a better prediction of how these maneuvers may or may not affect dysphonic speakers. In this way, clinicians will be able to refine techniques while tailoring exercises to meet a specific patient's vocal needs. This understanding may also assist us to find the best ways to maximize vocal performance when that performance is shared with other forms of physical labor. To date, there have been very few objective studies that document the effects of strenuous upper-limb activity on vocal function, in either dysphonic or normal speakers. The present investigation was designed to provide preliminary data on voice production for vocally healthy speakers engaged in a weight support task.

\section{Method}

Subjects

Ten men, ages $27-41$ years $($ mean $=34.0$ years, $S D=4.3)$ and 10 women, ages $25-39$ years ( mean $=32.2$ years, $S D=5.0$ ), served as subjects. All subjects were vocally healthy and none reported a history of respiratory, vocal or auditory pathology. None of the subjects had received any formal vocal or athletic training. Each subject's height and weight were measured at the time of testing. The male subjects ranged in height from 1.73 to $1.83 \mathrm{~m}$ (mean = $1.78 \mathrm{~m})$ and in weight from 70.8 to $95.2 \mathrm{~kg}($ mean $=83.3 \mathrm{~kg})$. The female subjects were between 1.65 and $1.78 \mathrm{~m}$ tall (mean $=1.72 \mathrm{~m}$ ) and between 53.5 and $73.0 \mathrm{~kg}$ in weight (mean $=64.5 \mathrm{~kg}$ ). All subjects were primarily mesomorphic in body type.

\section{Experimental Procedure}

Each subject stood erect while supporting a weight (fixedweight dumbbell) in each hand. With arms held supine and straight before them, the subject first rested his or her hands on padded push switches attached to a crossbar that was adjusted to the subject's height at about the level of the umbilicus. Each subject sustained the vowel /a/ as steadily as possible at a self-selected comfortable pitch and loudness. After 3 s of phonation, the subject was instructed to lift the weights approximately $20 \mathrm{~cm}$ without interrupting phonation so that the arms remained straight, supine, and parallel to the floor. Phonation was continued for at least $3 \mathrm{~s}$ after the lift. Three randomized trials were obtained per subject for each of the following combined-weight conditions: 0 , 3,5 , and $7 \mathrm{~kg}$. For the $0-\mathrm{kg}$ condition the subject performed the identical task with closed fists without dumbbells.

To allow a subsequent estimate of subglottal pressure and laryngeal airway resistance $[36,37]$, the subjects repeated the weightlifting task for each of the experimental conditions while repeating the syllable /pi/. A metronome, set for 92 beats per minute (andante), helped keep the repetition rate at a fairly constant 1.5 syllables per second.

\section{Data Acquisition}

The two-channel-average output of a model MC2-1 Glottal Enterprises (Syracuse, N.Y., USA) electroglottograph was used to obtain the subject's EGG. The EGG electrodes were positioned on the anterior neck at the level of the vocal folds and held in place by a firmly fitting flexible neckband. The linear phase circuitry of the instrument provided $20-\mathrm{Hz}$ high-pass filtering that served to minimize baseline shift and nonvocal influences on the EGG waveform [37-39].

Phonatory airflow was measured by means of a circumferentially vented pneumotachograph (Rothenberg) mask and a PTW-1 pressure transducer supported by an elastic head harness. The transducer was connected to a Glottal Enterprises MSIF-2 preamplifier that low-pass-filtered the flow signal using a $50-\mathrm{Hz}$ cutoff frequency. The airflow system was calibrated separately for each subject using a Glottal Enterprises MCU-2 calibration unit that includes a rotameter connected in series with a fitted holder for the mask assembly.

For those trials requiring /pi/-syllable repetition, a thin, short catheter was passed through a fitting in the face mask and positioned between the subject's lips to an approximate location directly behind the upper incisors. The other end of the catheter was connected to a differential pressure transducer (Glottal Enterprises) with a flat frequency response up to about $30 \mathrm{~Hz}$ to obtain the intraoral pressure signal. Calibration of air pressure was performed for each subject using a syringe and U-tube manometer [37].

An electret microphone inserted into the central handle of the mask was used to obtain the sound pressure signal for assistance with the subsequent identification of phonatory segments. All 
Table 1. Means \pm SD for the male subjects producing sustained phonation

\begin{tabular}{lllllll}
\hline Condition & $\mathrm{F}_{0}, \mathrm{~Hz}$ & $\mathrm{~F}_{0}-\mathrm{CV}, \%$ & Jitter, PPQ, $\%$ & EGG CQ, \% & Airflow, ml/s \\
\hline $0 \mathrm{~kg}$ & $\begin{array}{l}\text { before lift } \\
\text { after lift }\end{array}$ & $117.6 \pm 9.9$ & $0.86 \pm 0.21$ & $0.401 \pm 0.133$ & $53.3 \pm 4.3$ & $157.9 \pm 20.8$ \\
& $118.4 \pm 9.7$ & $0.91 \pm 0.28$ & $0.420 \pm 0.147$ & $53.3 \pm 3.7$ & $152.4 \pm 15.0$ \\
\hline $3 \mathrm{~kg}$ & before lift & $119.3 \pm 10.8$ & $0.82 \pm 0.22$ & $0.401 \pm 0.131$ & $52.8 \pm 2.6$ & $147.8 \pm 16.3$ \\
& after lift & $119.0 \pm 10.7$ & $0.94 \pm 0.26$ & $0.424 \pm 0.172$ & $54.9 \pm 3.4$ & $147.5 \pm 15.5$ \\
\hline $5 \mathrm{~kg}$ & before lift & $120.8 \pm 11.0$ & $0.80 \pm 0.14$ & $0.409 \pm 0.141$ & $52.8 \pm 2.6$ & $147.6 \pm 11.0$ \\
& after lift & $120.1 \pm 10.9$ & $1.07 \pm 0.25$ & $0.435 \pm 0.175$ & $56.2 \pm 3.8$ & $133.8 \pm 15.6$ \\
\hline $7 \mathrm{~kg}$ & before lift & $120.2 \pm 10.3$ & $0.74 \pm 0.11$ & $0.424 \pm 0.154$ & $53.0 \pm 3.4$ & $151.3 \pm 15.7$ \\
& after lift & $121.1 \pm 10.5$ & $1.46 \pm 0.26$ & $0.501 \pm 0.116$ & $58.5 \pm 5.3$ & $141.5 \pm 20.9$ \\
\hline \multirow{2}{*}{ Total } & before lift & $119.5 \pm 10.3$ & $0.80 \pm 0.18$ & $0.409 \pm 0.135$ & $53.0 \pm 3.2$ & $151.2 \pm 16.2$ \\
& after lift & $119.6 \pm 10.1$ & $1.10 \pm 0.34$ & $0.445 \pm 0.152$ & $55.7 \pm 4.4$ & $143.8 \pm 17.7$ \\
\hline
\end{tabular}

signals (EGG, sound pressure, airflow, and air pressure) were sampled at $40 \mathrm{kHz}$ using an Alamed (Vega, Tex., USA) SIU-2 signal interface and customized Alamed Acquire software running a 12-bit Data Translation DT2821G A/D converter.

\section{Measurements}

The subject's vocal $\mathrm{F}_{0}$, fundamental frequency coefficient of variation $\left(\mathrm{F}_{0}-\mathrm{CV}\right)$, and mean percent jitter were derived from the EGG signal. Reported data were obtained for a 1-second voice sample that concluded $1 \mathrm{~s}$ before weightlifting and for a 1-second sample that began $1 \mathrm{~s}$ after both weights had been lifted. The instant of weightlifting was identified via the crossbar armrest switches. Vocal cycles were demarcated by positive going (increasing vocal-fold contact) zero crossings using linear interpolation techniques. Jitter was defined as the 5-cycle averaged pitch perturbation quotient (PPQ). The EGG contact quotient (CQ), the vocal-fold contact duty cycle, was also measured. The CQ was defined as the percentage of the vibratory cycle above a variable zero cross of the interpolated 25\% peak-to-peak EGG amplitude. This measure, sometimes called EGGW-25, has been shown to provide a reasonable index of vocal-fold adduction [37-41].

For sustained phonations, the mean phonatory airflow was determined from the calibrated flow trace for the same 1-second intervals used to derive the EGG-based measures. For those trials in which subjects were instructed to repeat the syllable /pi/, the subglottal pressure was estimated from the peak $/ \mathrm{p} /$ intraoral pressure, whereas the phonatory flow rate was averaged from the mid-vowel portion of the airflow trace [36,37]. Pressure, flow, and the derived laryngeal airway resistance were averaged across 5 syllables produced before the lift and across 5 syllables produced during weight support.

Statistical Analysis

Data from the male and female subjects for the sustained phonation and syllable-repetition tasks were analyzed via a repeated measures analysis of variance (ANOVA) model using SPSS 14.0 for Windows software.

\section{Results}

\section{Sustained Phonation}

Summary data for the male and female subjects are shown in tables 1 and 2, respectively. The mean pre-lift $\mathrm{F}_{0}$, long-term $\left(\mathrm{F}_{0}-\mathrm{CV}\right)$ and short-term $(\mathrm{PPQ}) \mathrm{F}_{0}$ variation, EGG CQ, and phonatory airflow were consistent with previous studies of phonation sustained by normal men and women at a self-selected 'comfortable' pitch [3744]. For the data obtained before the lift, neither group of subjects showed a statistical difference $(p>0.05)$ for any of the measures between the weight conditions. Therefore, measured phonatory characteristics were comparable prior to lifting and sustaining the differing weights, suggesting that the anticipation of effort did not have a substantive effect on phonatory behavior.

For data obtained during weight support, results were consistent for both the male and female subjects. The mean vocal $\mathrm{F}_{0}, \mathrm{PPQ}$, and phonatory airflow did not differ significantly $(p>0.05)$ from the pre-lift data or between weight conditions. CQ values, however, were significantly different between weight conditions for both the men $[F(3,36)=2.96, p<0.05]$ and women $[F(3,36)=5.74, p<$ 0.01]. A more salient difference was seen for the coefficient of variation of vocal $\mathrm{F}_{0}$. Long-term variation increased significantly by weight condition across male $[\mathrm{F}(3,36)=12.29, \mathrm{p}<0.001]$ and female $[\mathrm{F}(3,36)=9.02$, $\mathrm{p}<0.001]$ subjects.

Figure 1 shows representative data traces for a male subject during the 5-kg lift and support task. Note that approximately $150 \mathrm{~ms}$ prior to lifting the dumbbells from the supportive crossbar, there is an increase in $\mathrm{F}_{0}$ instability, a drop in the mean flow rate, and an increase 
Fig. 1. Partial data traces from a male subject sustaining phonation during the $5-\mathrm{kg}$ task.
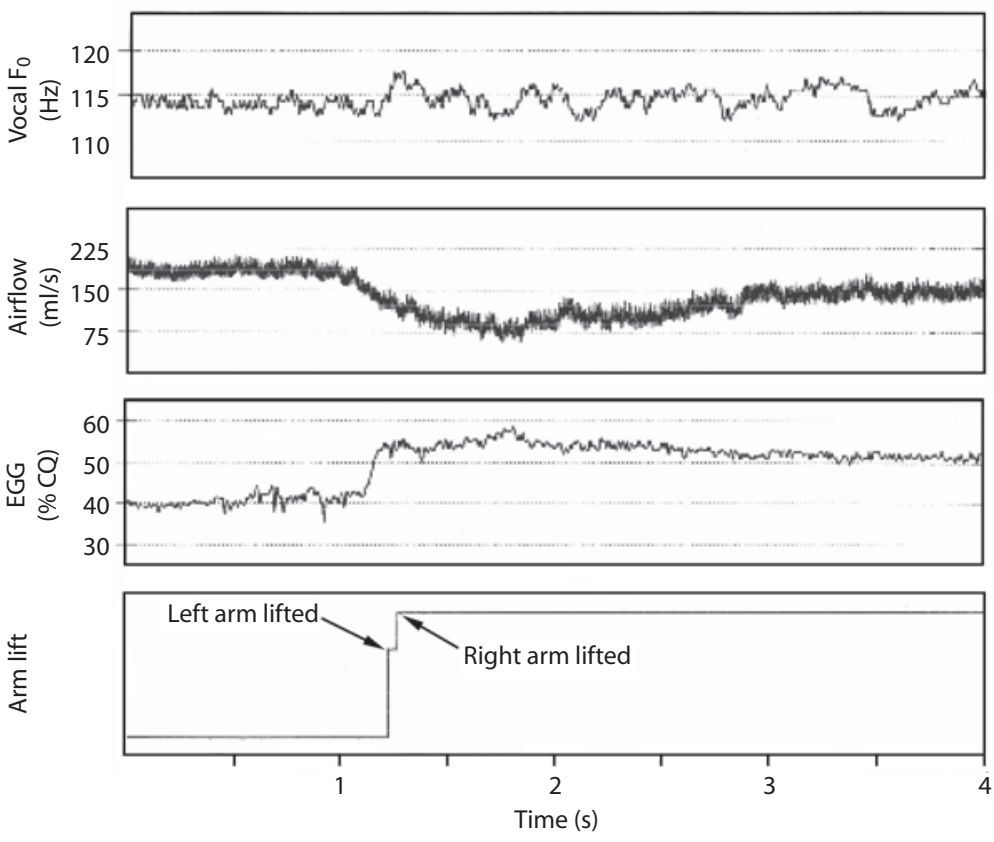

Table 2. Means \pm SD for the female subjects producing sustained phonation

\begin{tabular}{lllllll}
\hline Condition & $\mathrm{F}_{0}, \mathrm{~Hz}$ & $\mathrm{~F}_{0}-\mathrm{CV}, \%$ & Jitter, PPQ, $\%$ & EGG CQ, \% & Airflow, ml/s \\
\hline \multirow{2}{*}{$\mathrm{kg}$} & before lift & $212.7 \pm 15.2$ & $0.91 \pm 0.20$ & $0.456 \pm 0.128$ & $48.7 \pm 5.1$ & $133.9 \pm 9.4$ \\
& after lift & $213.4 \pm 15.8$ & $0.85 \pm 0.18$ & $0.458 \pm 0.122$ & $48.8 \pm 4.8$ & $137.9 \pm 15.6$ \\
\hline $3 \mathrm{~kg}$ & before lift & $214.7 \pm 14.8$ & $0.86 \pm 0.17$ & $0.473 \pm 0.158$ & $49.8 \pm 5.2$ & $134.9 \pm 15.4$ \\
& after lift & $214.9 \pm 14.1$ & $0.88 \pm 0.12$ & $0.509 \pm 0.140$ & $50.2 \pm 4.7$ & $139.6 \pm 30.4$ \\
\hline $5 \mathrm{~kg}$ & before lift & $213.8 \pm 14.5$ & $0.86 \pm 0.17$ & $0.479 \pm 0.162$ & $50.3 \pm 4.7$ & $131.5 \pm 25.1$ \\
& after lift & $224.0 \pm 39.8$ & $1.01 \pm 0.25$ & $0.495 \pm 0.172$ & $52.1 \pm 5.4$ & $128.9 \pm 20.7$ \\
\hline $7 \mathrm{~kg}$ & before lift & $215.5 \pm 14.1$ & $0.82 \pm 0.16$ & $0.465 \pm 0.157$ & $50.5 \pm 5.4$ & $128.7 \pm 22.4$ \\
& after lift & $216.5 \pm 13.9$ & $1.30 \pm 0.16$ & $0.524 \pm 0.183$ & $57.5 \pm 6.4$ & $126.6 \pm 21.7$ \\
\hline Total & before lift & $217.2 \pm 23.0$ & $0.86 \pm 0.17$ & $0.468 \pm 0.146$ & $49.8 \pm 5.0$ & $132.2 \pm 18.5$ \\
& after lift & $212.7 \pm 22.1$ & $1.01 \pm 0.25$ & $0.496 \pm 0.152$ & $52.2 \pm 5.9$ & $133.3 \pm 22.6$ \\
\hline
\end{tabular}

in the EGG contact duty cycle. As was the tendency for the majority of subjects at the higher weight conditions, the flow reaches a nadir shortly after the lift and then begins to increase toward its pre-lift status as the weight is supported. Conversely, the $\mathrm{F}_{0}-\mathrm{CV}$ and $\mathrm{CQ}$ do not demonstrate any substantial drift during weight support.

\section{Syllable Repetition}

Summary data for the male and female subjects obtained during the syllable-repetition task are shown in tables 3 and 4, respectively. As with the sustained phonation task, there were no significant differences in pressure, flow or resistance ( $p>0.05$ ) between weight conditions while the crossbar supported the subjects' hands. The estimated mean $\mathrm{P}_{\mathrm{s}}$, mid-vowel airflow, and derived 
Table 3. Means \pm SD for the male subjects repeating the syllable /pi/

\begin{tabular}{lllll}
\hline Condition & $\begin{array}{l}\text { Estimated } \mathrm{P}_{\mathrm{s}} \\
\mathrm{cm} \mathrm{H}_{2} \mathrm{O}\end{array}$ & $\begin{array}{l}\text { Mid-vowel } \\
\text { airflow, } 1 / \mathrm{s}\end{array}$ & $\begin{array}{l}\text { Estimated } \mathrm{R}_{\text {law }} \\
\mathrm{cm} \mathrm{H}_{2} \mathrm{O} / \mathrm{l} / \mathrm{s}\end{array}$ \\
\hline $0 \mathrm{~kg}$ & $\begin{array}{l}\text { before lift } \\
\text { after lift }\end{array}$ & $\begin{array}{l}6.50 \pm 0.52 \\
6.42 \pm 0.50\end{array}$ & $\begin{array}{l}0.170 \pm 0.033 \\
0.177 \pm 0.025\end{array}$ & $39.3 \pm 7.3$ \\
\hline $3 \mathrm{~kg}$ & $\begin{array}{l}\text { before lift } \\
\text { after lift }\end{array}$ & $6.50 \pm 0.66$ & $0.182 \pm 0.032$ & $36.5 \pm 6.5$ \\
\hline $5 \mathrm{~kg}$ & $\begin{array}{l}\text { before lift } \\
\text { after lift }\end{array}$ & $6.66 \pm 0.59$ & $0.172 \pm 0.019$ & $40.0 \pm 7.2$ \\
\hline $7 \mathrm{~kg}$ & $\begin{array}{l}\text { before lift } \\
\text { after lift }\end{array}$ & $6.60 \pm 0.50$ & $0.194 \pm 0.031$ & $34.6 \pm 4.3$ \\
& $8.73 \pm 1.05$ & $0.176 \pm 0.036$ & $40.2 \pm 7.0$ \\
\hline Total & before lift & $6.55 \pm 0.56$ & $0.181 \pm 0.034$ & $38.7 \pm 7.6$ \\
& after lift & $7.30 \pm 1.11$ & $0.179 \pm 0.030$ & $48.4 \pm 7.5$ \\
\hline & & & & $37.3 \pm 6.6$ \\
\hline
\end{tabular}

estimate of $\mathrm{R}_{\text {law }}$ were consistent with values obtained in previous investigations $[36,37,44,45]$.

As is common in syllable repetition and spontaneous speech, the mid-vowel airflow was slightly higher than the mean flow measured during sustained phonation [37]. Consistent with the subjects' flow data for prolonged phonation there were no significant differences $(p>0.05)$ in average mid-vowel flow across weight conditions for either sex. However, there was a significant increase in estimated $\mathrm{P}_{\mathrm{s}}$ as the men $[\mathrm{F}(3,36)=20.44, \mathrm{p}<0.001]$ and women $[\mathrm{F}(3,36)=12.29, \mathrm{p}<0.001]$ supported heavier weights. Given the increased pressure in the face of a midvowel airflow that essentially went unchanged, it is not surprising that the derived $\mathrm{R}_{\text {law }}$ estimate was significantly different across weight-support conditions for both the male $[\mathrm{F}(3,36)=6.77, \mathrm{p}<0.001]$ and female $[\mathrm{F}(3,36)=$ $20.44, \mathrm{p}<0.001]$ subjects. During an interview held with the subjects following study participation, it was generally reported that weightlifting while repeating syllables was more difficult and required more effort than when they were required to weightlift while sustaining phonation. The majority of subjects reported that lifting and supporting a combined weight of $7 \mathrm{~kg}$ was close to their limit given the posture and technique prescribed.

\section{Discussion}

According to Aronson [18], activities such as controlled coughing, grunting, pushing, and lifting trigger an 'effort closure reflex' that facilitates glottal competence. Wilson [17] attributes improved airway dynamics
Table 4. Means \pm SD for the female subjects repeating the syllable /pi/

\begin{tabular}{|c|c|c|c|c|}
\hline \multicolumn{2}{|c|}{ Condition } & \multirow{2}{*}{$\begin{array}{l}\begin{array}{l}\text { Estimated } \mathrm{P}_{\mathrm{s}} \\
\mathrm{cm} \mathrm{H} \mathrm{H}_{2} \mathrm{O}\end{array} \\
6.14 \pm 0.76\end{array}$} & \multirow{2}{*}{$\begin{array}{l}\begin{array}{l}\text { Mid-vowel } \\
\text { airflow, } 1 / \mathrm{s}\end{array} \\
0.144 \pm 0.021\end{array}$} & \multirow{2}{*}{$\begin{array}{l}\begin{array}{l}\text { Estimated } \mathrm{R}_{\text {lan }} \\
\mathrm{cm} \mathrm{H} \mathrm{H}_{2} \mathrm{O} / \mathrm{l} / \mathrm{s}\end{array} \\
43.4 \pm 8.2\end{array}$} \\
\hline $0 \mathrm{~kg}$ & before lift & & & \\
\hline & afte & $5.92 \pm 0.89$ & $0.139 \pm 0.020$ & $43.2 \pm 7.4$ \\
\hline \multirow[t]{2}{*}{$3 \mathrm{~kg}$} & befo & $5.99 \pm 0.90$ & $0.141 \pm 0.034$ & 44.5 \\
\hline & afte & $6.04 \pm 0.76$ & $0.139 \pm 0.019$ & $43.9 \pm 7.0$ \\
\hline \multirow[t]{2}{*}{$5 \mathrm{~kg}$} & before lift & $6.67 \pm 0.57$ & $0.153 \pm 0.019$ & $44.3 \pm 7.8$ \\
\hline & after & $7.51 \pm 0.57$ & $0.156 \pm 0.029$ & $49.7 \pm 10.5$ \\
\hline \multirow[t]{2}{*}{$7 \mathrm{~kg}$} & before lift & $6.28 \pm 0.67$ & $0.134 \pm 0.022$ & $48.0 \pm 8.8$ \\
\hline & after lift & $8.65 \pm 1.32$ & $0.155 \pm 0.030$ & $56.9 \pm 8.2$ \\
\hline \multirow[t]{2}{*}{ Total } & before lift & $6.27 \pm 0.75$ & $0.143 \pm 0.025$ & $45.1 \pm 8.7$ \\
\hline & after lift & $7.03 \pm 1.45$ & $0.147 \pm 0.025$ & $48.4 \pm 9.8$ \\
\hline
\end{tabular}

to the resulting increase in laryngeal muscle tonus, whereas Yamaguchi et al. [22] assert that occluding the glottis is necessary to build sufficient thoracic pressure to perform such tasks effectively. Like sustained pushing and pulling against a resistant object, lifting and supporting hand-held weights represents a modified Valsalva maneuver that requires breath restraint while necessarily losing air volume owed to voice production.

Although active pushing, pulling, and various forms of isometric exercises have been employed in the treatment of several different vocal pathologies, there remains concern about the appropriateness of their use. Colton et al. [29], for instance, have questioned the efficacy of effort closure techniques except when used to treat a few carefully selected types of functional voice disorders, and only then when the patient performs them while producing a low-pitched 'forceful grunt' with the larynx positioned low within the neck. Although laryngeal height was not measured in the present study, it is interesting that the act of weightlifting did not, in and of itself, result in a significant change in mean vocal $\mathrm{F}_{0}$. However, it is also important to note that, unlike voice patients in a therapeutic setting, the present subjects were free of vocal pathology and were attempting to maintain their comfortable phonation despite the effort of lifting. Nonetheless, as had the asthenic patients performing Yamaguchi et al.'s [22] pushing exercise, the subjects in this study did evince an increase in relative vocal-fold contact duration upon weightlifting.

An increase in EGG CQ suggests that upper-limb weight support resulted in greater medial compression during phonation. Along with CQ changes, the subjects 
showed a significantly greater laryngeal airway resistance attributable to an increased driving pressure rather than to a reduction in mean phonatory airflow. These results are consistent with experimental evidence that suggests that the flow rate serves as a control parameter in speech $[10,46]$. Although the EGG reflects consequent changes in vocal-fold contact behavior, the technique is insensitive to the types of glottal adjustments [37] that could be employed to maintain the aerodynamic integrity of the speech system. Unknown also is whether the present subjects applied any significant supraglottal airway compensation as has been reported by some investigators for subjects performing breath-holding or other tasks requiring forced closure [7, 18, 47]. Of particular note, however, is the observation that the normal subjects tested by Beaty et al. [48] consistently showed supraglottic dilation during 'progressively strenuous' exercise.

Data traces from the subjects clearly suggested that the most dramatic vocal changes occurred during and just after the act of lifting the dumbbells, and indeed, many voice clinicians [e.g., 12-15] have stressed the importance of coordinating a patient's phonation with the point of maximal physical effort for the technique to be effective. This is different from the isometric steady-state lift in the present experiment or the push or pull against an immovable object as is commonly employed in voice therapy [e.g., 22, 26-28]. Naito and Niimi [11] endoscopically observed the laryngeal behavior of 12 healthy subjects as they performed various strenuous activities that involved the upper limbs, such as pushing themselves up onto a horizontal bar and striking an object. They noted glottal closure consistently at the moment of maximum exertion, but reported far greater variability in airway status during intervals of constant effort.

\section{Conclusion}

The results of this study indicate that phonation produced during weightlifting is associated with increased laryngeal airway resistance characterized by an elevation in driving pressure and medial compression of the vocal folds. There was no significant change in mean $\mathrm{F}_{0}$, jitter, or phonatory airflow between the pre-lift and lift portions of the subjects' sustained phonation, regardless of the amount of weight supported. Unlike the other variables measured, the phonatory flow rate tended to decrease during the lifting maneuver, but then rebounded as the task became one of stable support.

Additional work is needed to extend this investigation to other forms of physical effort, to compare the effects of static isometric and dynamic isotonic exercises, and to begin systematic study of dysphonic speakers. In doing so, it may be useful to track changes beyond laryngeal airway resistance and vocal-fold medial compression. The combined use of EGG and techniques such as photoglottography and high-speed video endoscopy, for instance, may provide valuable insight regarding glottal dynamics and the speed of vocal-fold approximation that are likely to be important in the development of many types of vocal pathology as well as in its management.

\section{Acknowledgments}

Portions of this research study were conducted at Memorial Sloan-Kettering Cancer Center in New York and at Hunter College of the City University of New York. The author would like to thank Prof. Harm K. Schutte and 2 anonymous reviewers for their careful overview of the manuscript and helpful comments.

\section{References}

1 Bartlett D Jr: Respiratory functions of the larynx. Physiol Rev 1989;60:33-57.

$\checkmark 2$ Brunton TL, Cash T: The valvular action of the larynx. J Anat Physiol 1883;17:363-368.

3 Davis PR, Troup JDG: Pressures in the trunk cavities when pulling, pushing and lifting. Ergonomics 1964;7:464-474.

$\checkmark 4$ Davis PR: Trunk mechanics and intra-truncal pressures. J Anat 1969;105:185-186.

$\checkmark 5$ Compton D, Hill PM, Sinclair JD: Weightlifters' blackout. Lancet 1973;ii:1234-1237.

6 Hayama S, Honda K, Oka H, Okada M: Air trapping and arboreal locomotor adaptation in primates: a review of experiments on humans. Z Morphol Anthropol 2002;83:149159.
7 Fink BR: The curse of Adam: effort closure of the larynx. Anesthesiology 1973;39:325327.

8 Bartelink DL: The role of the abdominal pressure in relieving the pressure on the lumbar intervertebral discs. J Bone Joint Surg 1957;39B:718-725.

9 Morris JM, Lucas DB, Bresler B: Role of the trunk in stability of the spine. J Bone Joint Surg 1961;43A:327-351.

10 Doust JH, Patrick JM: The limitation of exercise ventilation during speech. Respir Physiol 1981;46:137-147.

11 Naito A, Niimi S: The larynx during exercise. Laryngoscope 2000;110:1147-1150.
12 Hagins M, Lamberg EM: Natural breath control during lifting tasks: effect of load. Eur J Appl Physiol 2006;96:453-458.

13 Froeschels E, Kastein S, Weiss DA: A method of therapy for paralytic conditions of the mechanisms of phonation, respiration, and glutination. J Speech Hear Disord 1955;20: 365-370.

14 Weiss DA: Introduction to Functional Voice Therapy. Basel, Karger, 1971, pp 21-22.

15 Brodnitz FS: Vocal Rehabilitation: A Manual Prepared for the Use of Graduates in Medicine, ed 4. Rochester, American Academy of Ophthalmology and Otolaryngology, 1971, pp 100-101. 
16 Prater RJ, Swift RW: Manual of Voice Therapy. Boston, Little, Brown, 1984, pp 190191.

17 Wilson DK: Voice Problems of Children, ed 3. Baltimore, Williams \& Wilkins, 1987, pp 226-228.

18 Aronson AE: Clinical Voice Disorders, ed 3. New York, Thieme, 1990, pp 24-26, 340.

-19 Pannbacker M: Voice treatment techniques: a review and recommendations for outcome studies. Am J Speech Lang Pathol 1998;7:4964.

20 Solomon NP, Charron S: Speech breathing in able-bodied children and children with cerebral palsy: a review of the literature and implications for clinical intervention. Am J Speech Lang Pathol 1998;7:61-78.

21 Duffy JR: Motor Speech Disorders: Sub strates, Differential Diagnosis, and Management, ed 2. St Louis, Elsevier Mosby, 2005, p 472.

22 Yamaguchi H, Yotsukura Y, Sata H, Watanabe Y, Hirose H, Kobayashi N, Bless DM: Pushing exercise program to correct glottal incompetence. J Voice 1993;7:250-256.

23 Ramig LO, Scherer RC: Speech therapy for neurologic disorders of the larynx; in Blitzer A, Brin MF, Sasaki CT, Fahn S, Harris KS (eds): Neurological Disorders of the Larynx. New York, Thieme, 1992, pp 163-181.

24 Dromey C, Ramig LO, Johnson AB: Phonatory and articulatory changes associated with increased vocal intensity in Parkinson disease: a case study. J Speech Hear Res 1995; 38:751-764.

-25 Ramig LO, Dromey C: Aerodynamic mechanisms underlying treatment-related changes in vocal intensity in patients with Parkinson disease. J Speech Hear Res 1996;39:798807.

-26 Ramig LO, Sapir S, Fox C, Countryman S Changes in vocal loudness following intensive voice treatment (LSVT) in individuals with Parkinson disease: a comparison with untreated patients and normal age-matched controls. Mov Disord 2001;16:79-83.
27 Aldes MEB: Hysterical high pitch in an adult female: a case study. J Commun Disord 1981; 14:59-64.

28 Maniecka-Aleksandrowicz B, DomerackaKołodziej A, Rózak-Komorowska A, Szeptycka-Adamus A: Postępowanie i leczenie w afonii psychogennej: analiza 500 przypadków (Management and therapy in functional aphonia: analysis of 500 cases). Otolaryngol Pol 2006;60:191-197.

29 Colton RH, Casper J, Leonard RB: Understanding Voice Problems: A Physiological Perspective for Diagnosis and Treatment, ed 3. Baltimore, Lippincott Williams \& Wilkins, 2006, pp 348-349.

30 Otis AB, Clark RG: Ventilatory implications of phonation and phonatory implications of ventilation. Ann NY Acad Sci 1968;155:122128.

31 Andrews M, Shank KH: Some observations concerning the cheering behavior of schoolgirl cheerleaders. Lang Speech Hear Serv Schools 1983;14:150-156.

32 Reich A, McHenry M, Keaton A: A survey of dysphonic episodes in high-school cheerleaders. Lang Speech Hear Serv Schools 1986;17:63-71.

33 Heidel SE, Torgerson JK: Vocal problems among aerobic instructors and aerobic participants. J Commun Disord 1993;26:179191.

34 Long J, Williford HN, Olson MS, Wolfe V: Voice problems and risk factors among aerobics instructors. J Voice 1998;12:197-207.

35 Wolfe V, Long J, Youngblood HC, Williford $\mathrm{H}$, Olson MS: Vocal parameters of aerobic instructors with and without voice problems. J Voice 2002;16:52-60.

36 Smitheran JR, Hixon TJ: A clinical method for estimating laryngeal airway resistance during vowel production. J Speech Hear Disord 1981;46:138-146.

37 Baken RJ, Orlikoff RF: Clinical Measurement of Speech and Voice, ed 2. San Diego, Singular Thomson, 2000.
38 Orlikoff RF: Electroglottographic assessment of voice; in Kent RD (ed): MIT Encyclopedia of Communication Sciences and Disorders. Cambridge, MIT Press, 2003, pp 23-27.

39 Orlikoff RF: Assessment of the dynamics of vocal fold contact from the electroglottogram: data from normal male subjects. J Speech Hear Res 1991;34:1066-1072.

40 Scherer RC, Vail VJ, Rockwell B: Examination of the laryngeal adduction measure EGGW; in Bell-Berti F, Raphael LJ (eds): Producing Speech: Contemporary Issues for Katherine Stafford Harris. New York, AIP Press, 1995, pp 269-289.

41 Herbst C, Ternström S: A comparison of different methods to measure the EGG contact quotient. Logop Phoniatr Vocol 2006;31: 126-138.

42 Orlikoff RF, Baken RJ: Consideration of the relationship between the fundamental frequency of phonation and vocal jitter. Folia Phoniatr 1990;42:31-40.

43 Higgins MB, Saxman JH: A comparison of intrasubject variation across session of three vocal frequency perturbation indices. J Acoust Soc Am 1989;86:911-916.

44 Higgins MB, Saxman JH: A comparison of selected phonatory behaviors of healthy aged and young adults. J Speech Hear Res 1991;34: 1000-1010.

45 Higgins MB, Netsell R, Schulte L: Aerodynamic and electroglottographic measures of normal voice production: intrasubject variability within and across sessions. J Speech Hear Res 1994;37:38-45.

46 Laine T, Warren DW, Dalston RM, Hairfield WM, Morr KE: Intraoral pressure, nasal pressure and airflow rate in cleft palate speech. J Speech Hear Res 1988;31:432-437.

47 Martin BJW, Logemann JA, Shaker R, Dodds WJ: Normal laryngeal valving patterns during three breath-hold maneuvers: a pilot investigation. Dysphagia 1993;8:11-20.

48 Beaty MM, Wilson JS, Smith RJ: Laryngeal motion during exercise. Laryngoscope 1999; 109:136-139. 